\title{
Galileo on speed
}

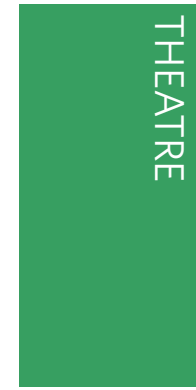

The audience files into the theatre taking their seats around - and in fact on - the circular stage. The staging is minimal: a few chairs, a lamp/telescopestand and a rickety staircase along the periphery of the stage. Electronic music, written by Tom Rowlands of Chemical Brothers fame, blares through the speakers as the actors dance around, pumping up the audience. Brendan Cowell - our Galileo for the evening and until 1 July - announces 'Scene 1'. A short puppet show sets the stage and we find Galileo in his house discussing with Andrea, his housekeeper's son and trusted student, Copernicus's heliocentric system. Soon thereafter Galileo builds his first telescope, following news of such a contraption being sold in the Netherlands, and it's not much later that he points it to the sky. At that moment, the planetarium-like screen overhanging the stage lights up with a starry night sky and then the Moon with its many craters, valleys and mountains.

Galileo realizes that the Moon is not that different from Earth. In the next scene he observes Jupiter's moons, which he names the Medici stars to appease the local lords. More importantly he realizes that they are orbiting around Jupiter. This movement is proof that Copernicus was indeed right and the 'divine' Aristotle's idea that stars are fixed atop 'crystal spheres' must be incorrect. This inadvertently brings Galileo in conflict with the Catholic Church and leads to his incarceration by the Inquisition, the infamous recantation of his work and eventually his death under house arrest in Arcetri, Italy in 1642.

Galileo's eventful life is mirrored in the pace of the screenplay and the frenzied direction. The scenes follow one another in rapid succession and Joe Wright - the director - throws a kaleidoscope of imagery at the audience. Scenes are interlaced with more puppetry performed in poetic prose, perhaps a way of detaching the audience from the happenings on stage and a throwback to the classical setting of the story. The cardinals' meeting in Rome is presented as a nightclub with seminaked dancers and pulsing music. Galileo's rise to fame is punctuated by a colourful, singing procession of boa-feathered, glittercovered characters, one of them carrying a grotesquely huge head (Galileo's perhaps?). The Inquisitors are presented wearing black leather trench coats and sunglasses, reminiscent of Hollywood Nazis.

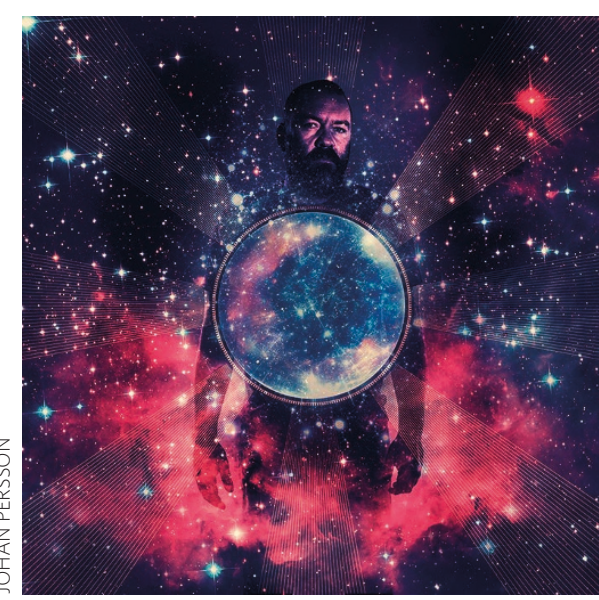

Although we see vignettes of Galileo's conflict with the Church on stage, the recantation itself happens off stage, harking back to the ancient Greek tragedies, with their unseen deaths. However, the most interesting exchanges happen between Galileo and Andrea and between Galileo and his friend Sagredo. It is then that we see glimpses of what motivates Galileo and where for me the heart of this play lies. Early on, in a sort of foreshadowing, Galileo makes a passionate plea for reason to his friend Sagredo. He wants to convince people that things on the sky move. His friend tries to dissuade him yet Galileo insists "if only they look with their eyes through the telescope" people will see reason; they will understand that Aristotle's model cannot be true. Fast-forward a few scenes and Cosimo de' Medici - ruler of Florence - is not allowed to even look through the telescope. If logic dictates that things are fixed on the sky, claims a cardinal, does it not follow that what one might see through the telescope is somehow wrong?
Writer Bertolt Brecht's Galileo is a scientist first and everything else second. $\mathrm{He}$ is driven by the shear excitement of new knowledge. Brendan Cowell portrays this excellently as he bounces around the stage, lectures his students and audience alike and argues for knowledge just for the sake of it. It is in Galileo's failures though — as a father, as a teacher and even as a scientist that we see his human side. His daughter suffers persistent disregard, his students are nothing more than a nuisance to him and when he eventually recants his theory, it is of fear for his corporal comfort. There is something particularly intelligent and noble yet naive and flawed about Brecht's Galileo.

The play resonated with me both as a scientist and as a citizen of the world. Galileo's complaints about performing irrelevant tasks to support his science struck too close to a reality that any scientist can attest to. I found myself drawing parallels between the reaction of the Church to Galileo and the obvious disdain about science and reason that has become a staple of modern politics. Galileo's almost religious defence of reason is echoed in the March for Science that took place all over the world last month. How far is our supposedly 'enlightened' society allegedly free of the shackles of dogmatic thought - from what Galileo had to face in the 17 th century? Which logic can we employ and through which lens should we look to break our own crystal spheres on the sky? As we see Galileo towards the later scenes, with golden confetti stuck to his bare feet, sweat soaking through his clothes and plastic handcuffs around his wrists, he is as far as one can get from the archetypal scientist. How do we avoid fighting the same fight against ignorance parading as divine truth? Breaking away from our proverbial ivory towers, shattering our (self-)imposed stereotypes and engaging with people young and old - scientists as well as non-scientists - may well be the answer.

\section{REVIEWED BY MARIOS KAROUZOS}

Life of Galileo is at the Young Vic, London until 1 July 2017. 